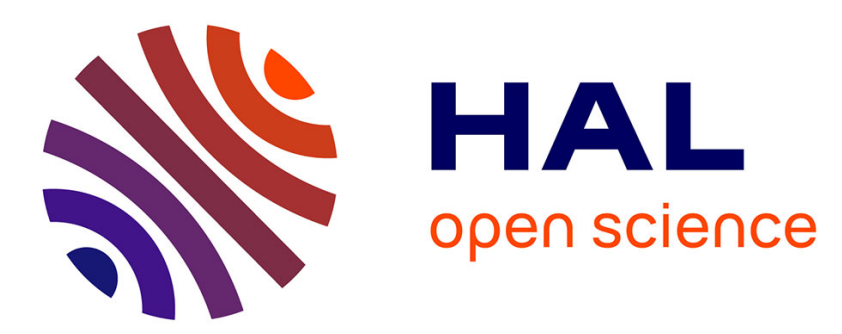

\title{
Effects of Touch Screen Response Time on Psychological State and Task Performance
}

\author{
Nozomi Sato, Kentaro Nakajima
}

\section{To cite this version:}

Nozomi Sato, Kentaro Nakajima. Effects of Touch Screen Response Time on Psychological State and Task Performance. 13th International Conference on Human-Computer Interaction (INTERACT), Sep 2011, Lisbon, Portugal. pp.507-510, 10.1007/978-3-642-23768-3_69 . hal-01596934

\section{HAL Id: hal-01596934 \\ https://hal.inria.fr/hal-01596934}

Submitted on 28 Sep 2017

HAL is a multi-disciplinary open access archive for the deposit and dissemination of scientific research documents, whether they are published or not. The documents may come from teaching and research institutions in France or abroad, or from public or private research centers.
L'archive ouverte pluridisciplinaire HAL, est destinée au dépôt et à la diffusion de documents scientifiques de niveau recherche, publiés ou non, émanant des établissements d'enseignement et de recherche français ou étrangers, des laboratoires publics ou privés. 


\title{
Effects of Touch Screen Response Time on Psychological State and Task Performance
}

\author{
Nozomi Sato $^{1}$, Kentaro Nakajima ${ }^{2}$ \\ ${ }^{1}$ Kinki University, Faculty of Applied Sociology, 3-4-1 Kowakae, Higashi-Osaka, Osaka \\ 577-8502 Japan \\ ${ }^{2}$ Fuji Xerox Co., Ltd, 9-7-3, Akasaka Minato-ku, Tokyo 107-0052 Japan \\ nozomi.satoh@socio.kindai.ac.jp
}

\begin{abstract}
The purpose of this study was to investigate how touch screen response time affected user's psychological state and task performance. Ten male participants performed numeric entry task on the touch screen under six different conditions by crossing speed of touch screen response for pressing buttons and of switching pages. Results suggested that the touch screen with the faster response time would be accepted more favorably than that with the slower response time. However, with regard to the results of task performance, opposite trend was obtained.
\end{abstract}

Keywords: touch screen response, psychological state, task performance

\section{Introduction}

Touch screen technology has become highly popular in our everyday life. It has been adopted not only for personal use such as home computer and audio equipment, but also for public use such as vending machine and automated teller machine. To improve user's psychological comfort in touch screen use, appropriate response time of touch screen for user's input is one of the essential issues. Time delay is a major source of annoyance with computing [1]. Much technological effort has been concentrated on shortening response time with computing. However, few studies have been conducted to investigate the negative effects of short response time of tough screen on user's psychological states and task performance. Therefore, the purpose of this study was to examine how touch screen response for pressing buttons and switching pages affected user's psychological state and task performance.

\section{Methods}

\subsection{Participants}

Ten male undergraduate students aged from 21to 24 years participated in this study. All participants were right-handed and had previous touch screen experience. They 
had normal or corrected to normal visual acuity and had no history of musculoskeletal diseases. Before enrolling in this study, written informed consent was obtained from all participants.

\subsection{Experimental task}

Participants performed the numeric entry task on the touch screen, using the forefinger (Fig. 1). The task was a 10-digit input with numerical keypad on the 17inch LCD touch screen (NT-7106, Nippon tect, Ltd.). 10-digits were displayed in the field on the top of the screen (Fig. 2). Participants were required to input the displayed digits with the numerical keypad. Actual digits that participants entered were displayed in the field in the middle of the screen (Fig. 3). Each trial was completed by pressing the button of the field (dotted line; Fig. 3). Six conditions were created by crossing speed of touch screen response for pressing buttons (1sec and 2sec), and speed of switching pages (1sec, 5sec, and 10sec). Participants completed whole conditions, each consisting of 10 trials.

\subsection{Measures}

Performance: To evaluate task performance, entry time for 10-digits of each trial was calculated by reducing touch screen response time from the time to complete the trial. Correct rate was also calculated for each condition.

Subjective time estimation: Previous study suggested that errors in estimation of durations could indicate the mental workload of the task [2]. Therefore, to evaluate mental workload while manipulating touch screen, subjective time estimation was conducted. Before the first condition and after each condition, participants were required to press a button of the stopwatch for a time period subjectively equal to 10 seconds.

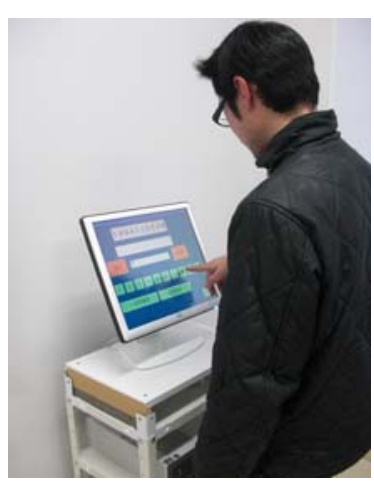

Fig. 1 Participant conducting entry task

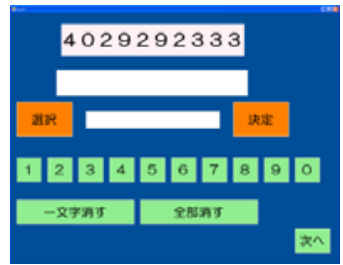

Fig. 2 Layout of the touch screen

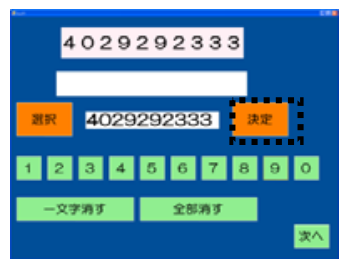

Fig. 3 An example of entered digits on the screen 
Behavioral observation: Behavioral observation is one of the useful methods for evaluating usability [3]. Participants' behavior while the task was recorded by the digital video camera (PCR-TRV70k, Sony Corporation) to investigate participants' psychological state such as irritation and hesitation.

Questionnaire: To evaluate participants' preference for each condition, SD method (semantic differential method) was conducted with 14 items, which was used in the previous study [4]. Responses were made on a 7-point scale from 1(strongly nonpreferable) to 7 (strongly preferable).

\subsection{Experimental procedure}

Following a brief training session, participants conducted subjective time estimation as a baseline. Then, they completed the numeric entry task under the six conditions. At the end of each of condition, they conducted the subjective time estimation and filled out the questionnaire. The order of condition was randomized for each participant.

\section{$3 \quad$ Results}

Performance: Entry time under different speed conditions for touch screen response time and the switching pages is presented in the Fig. 4. There was a significant main effect for speed of touch screen response $(F=42.19[1,9], p<0.01)$. The entry time for 2 sec touch screen was faster than that for 1 sec touch screen. No significant main effect and interaction was found for correct rate.

Subjective time estimation: Subjective time estimation under different speed conditions of touch screen response time is presented in the Fig. 5. There was a significant main effect for speed of touch screen response $(F=8.90[1,9], p<0.05)$. Participants estimated the time longer after the condition of $2 \mathrm{sec}$ response time than that of 1 sec response time.

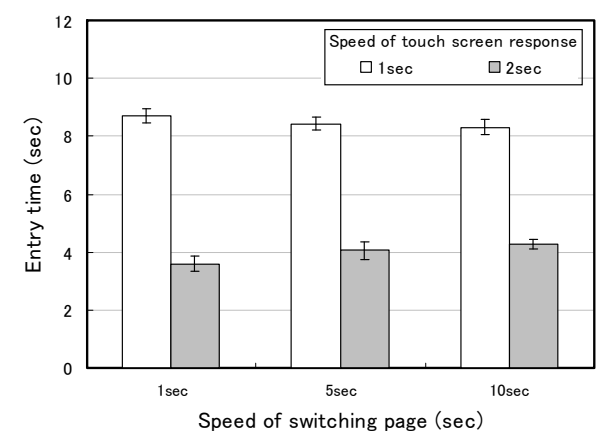

Fig. 4 Entry time for each condition. The error bars represent \pm standard error of the mean.

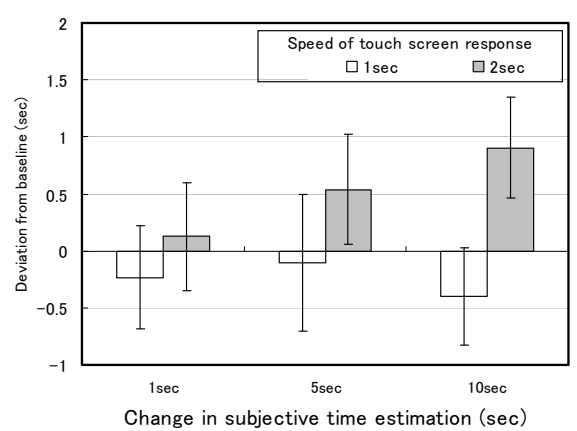

Fig. 5 Subjective time estimation after each condition. The error bars represent \pm standard error of the mean. 
Questionnaire: Preference score was obtained by averaging the total score of 14 items. Fig. 6 shows the preference score for each condition. Higher scores indicate greater preference. Friedman test was conducted to analyze data. There was a significant differences in preferred speed of touch screen response time and switching pages. Participants preferred touch screen response time with $1 \mathrm{sec}$ to that with 2 sec $(\mathrm{p}<0.01)$, and preferred switching page speed with 1 sec to other two speed conditions $(\mathrm{p}<0.05)$.

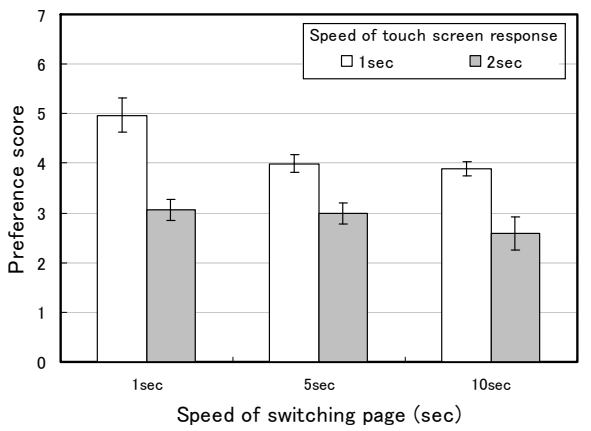

Fig. 6 Preference score for each condition. The error bars represent \pm standard error of the mean.

Behavioral observation: Statistically, there were no significant differences in the conditions. However, it was observed that some participants sighed or expressed restless behaviors such as tapping toe and shaking upper body slightly while response time and/or switching pages of touch screen were slow.

\section{Discussions}

Results from time estimation and questionnaire suggested that the time delay of touch screen button may negatively affect user's psychological state. Participants could have accepted more favorably the touch screen which responds in a shorter duration. However, task performance of the touch screen which responds with 1sec was worse than that with 2sec. Under the faster response time condition, participant had no enough time to move their fingers to the location of the button to be pressed although the system had been ready for accepting the entry. Changing of the layout of numerical keypad and/or adjusting the sensitivity of the touch screen would solve this problem. In the further study, the number of participants should be increased to confirm the reliability of results obtained from the current study.

\section{References}

1. Branaghan, R. J., Sanchez, C. A.: Feedback preference and impressions of waiting, Human Factors, 51, 528-538 (2009)

2. Lind, M., Sundvall, H.: Time estimation as a measure of mental workload, In, Proceedings of the 7th international conference on Engineering psychology and cognitive ergonomics, 359365, Springer-Verlag, Berlin, Heidelberg (2007)

3. Huang, H., Lai, H.-H.: Factors influencing the usability of icons in the LCD touchscreen, Displays, 29, 339-344 (2008)

4. Komatsubara, A., Yokomizo, Y, Yamamoto S., Noro, K.: Analysis of work load by computer system response time in different type of VDT tasks, The Japanese Journal of Ergonomics, 21, 211-217 (1985) 